\title{
Surgery is crucial for advanced esophageal squamous cell carcinoma after neoadjuvant chemoradiotherapy
}

\author{
Haiquan Chen, MD
}

\footnotetext{
From the Department of Thoracic Surgery, Fudan University Shanghai Cancer Center, Shanghai, China; and Department of Oncology, Shanghai Medical College, Fudan University, Shanghai, China.

Disclosures: Author has nothing to disclose with regard to commercial support.

Received for publication Feb 11, 2018; accepted for publication Feb 15, 2018; available ahead of print March 17, 2018.

Address for reprints: Haiquan Chen, MD, 270 Dong'an Rd, Shanghai 20032, China (E-mail: hqchen1@yahoo. com).

J Thorac Cardiovasc Surg 2018;155:2722-3

$0022-5223 / \$ 36.00$

Copyright (c) 2018 by The American Association for Thoracic Surgery

https://doi.org/10.1016/j.jtcvs.2018.02.042
}

Recent studies have established neoadjuvant treatment plus surgery as the standard treatment for advanced esophageal cancer. ${ }^{1,2}$ However, esophageal squamous cell carcinoma has a higher sensitivity to chemoradiotherapy, and esophageal surgery, one of the most invasive procedures and one that carries a high surgical risk, is associated with reduced quality of life. A clinical question thus is raised whether surgery is necessary for patients with advanced esophageal squamous cell carcinoma when they have a complete response after chemoradiation.

In the study by Barbetta and colleagues ${ }^{3}$ in this issue of the Journal, the results showed that neoadjuvant treatment plus surgery was associated with a lower risk of local recurrence and improved long-term survival. Notably, the study confirmed the importance of surgery in the treatment of advanced esophageal cancer after chemoradiation. The research is of great importance, because squamous cell carcinoma is the most common histologic type of esophageal cancer globally, and about half of the patients with this histologic type are found to have the tumor at an advanced stage. Although the study was limited by its retrospective nature, potential selection bias for the choice of treatment could be overcome by the use of propensity score matching, and patient and pretreatment characteristics were balanced between the 2 groups. Moreover, in consideration of potentially increased surgical risks after radiotherapy, the dose of radiation is generally reduced when future surgery is planned, whereas in this study, the dose of radiation was independent of surgical plans.

The topic of the research is of clinical relevance, and further studies are needed. Recently, Noordman and colleagues ${ }^{4}$ published the protocol for a planned steppedwedge cluster randomized trial that will compare neoadjuvant chemoradiotherapy plus surgery versus active surveillance of esophageal cancer. A total of 300 patients with clinically completer response after neoadjuvant chemoradiotherapy will be randomly allocated to determine the noninferiority of active surveillance to standard

\section{References} 681-92.

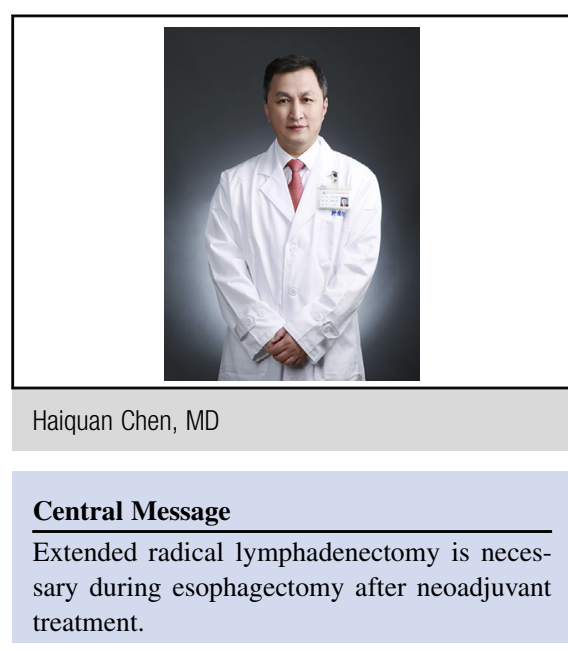

See Article page 2710 .

esophagectomy. The study hypothesizes that active surveillance leads to noninferior survival, improved quality of life, and a reduction in costs relative to standard esophagectomy.

At present, the comparisons of chemoradiation alone and chemoradiation followed by surgery have had conflicting results in published studies. One issue that should be noted is that surgical strategy varies worldwide, particularly with respect to the extent of lymphadenectomy. Squamous cell carcinoma of the esophagus is infrequently seen in Western countries, but it is the majority histologic type in China. My own group previously compared extended lymphadenectomy through a right thoracic approach and limited lymphadenectomy through a left thoracic approach for middle and lower thoracic esophageal squamous cell carcinoma, and our results indicated that patients with an advanced tumor stage would benefit from extended radical lymph node dissection, including total mediastinal and upper abdominal lymphadenectomy. ${ }^{5}$ Because of these varying results, the treatment protocol consisting of neoadjuvant chemoradiotherapy, esophagectomy, and extended radical lymphadenectomy needs to be studied further with respect to its role in managing esophageal squamous cell carcinoma.

1. van Hagen P, Hulshof MC, van Lanschot JJ, Steyerberg EW, van Berge Henegouwen MI, Wijnhoven BP, et al; CROSS Group. Preoperative chemoradiotherapy for esophageal or junctional cancer. N Engl J Med. 2012;366:2074-84.

2. Sjoquist KM, Burmeister BH, Smithers BM, Zalcberg JR, Simes RJ, Barbour A, et al. Survival after neoadjuvant chemotherapy or chemoradiotherapy for resectable oesophageal carcinoma: an updated meta-analysis. Lancet Oncol. 2011;12: 
3. Barbetta A, Hsu M, Tan KS, Stefanova D, Herman K, Adusumilli PS, et al. Definitive chemoradiotherapy versus neoadjuvant chemoradiotherapy followed by surgery for stage II to III esophageal squamous cell carcinoma. J Thorac Cardiovasc Surg. 2018;155:2710-21.e3.

4. Noordman BJ, Wijnhoven BP, Lagarde SM, Boonstra JJ, Coene PP, Dekker JW, et al; SANO-study group. Neoadjuvant chemoradiotherapy plus surgery versus active surveillance for oesophageal cancer: a stepped-wedge cluster randomised trial. BMC Cancer. 2018;18:142.

5. Li B, Hu H, Zhang Y, Zhang J, Miao L, Ma L, et al. Extended right thoracic approach compared with limited left thoracic approach for patients with middle and lower esophageal squamous cell carcinoma: three-year survival of a prospective, randomized, open-label trial. Ann Surg. 2018;267:826-32. 